\title{
Enzimas exógenas no desempenho e na digestibilidade ileal de nutrientes em frangos de corte
}

\author{
Nei André Arruda Barbosa ${ }^{(1)}$, Nilva Kazue Sakomura(1), João Batista Kochenborger Fernandes ${ }^{(2)}$ \\ e Leilane Rocha Barros Dourado(1)
}

\begin{abstract}
(1)Universidade Estadual Paulista (Unesp), Faculdade de Ciências Agrárias e Veterinárias, Departamento de Zootecnia, Via de Acesso Professor Paulo Donato Castellane, s/no, CEP 14884-900 Jaboticabal, SP. E-mail: neiandre@hotmail.com, sakomura@fcav.unesp.br, leilanerb@yahoo.com.br (2)Unesp, Centro de Aqüicultura. E-mail: jbatista@caunesp.unesp.br
\end{abstract}

Resumo - O objetivo deste trabalho foi avaliar o efeito da combinação de fitase e do complexo amilase, protease e xilanase, em dietas de milho e soja, formuladas com redução e sem redução dos níveis de energia, cálcio e fósforo sobre o desempenho e a digestibilidade ileal de nutrientes, em frangos de corte. Foi utilizado o delineamento inteiramente casualizado, com esquema fatorial 2x2, com duas dietas-controle: com redução e sem redução dos nutrientes, e duas suplementações das enzimas (sem adição e com adição de fitase e complexo enzimático), com dez repetições de 40 aves. A digesta ileal foi coletada aos 43 dias de idade, para determinação da energia digestível e dos coeficientes de digestibilidade da proteína bruta, matéria seca, cálcio e fósforo. O desempenho apresentou interação em todos os parâmetros analisados. As aves do tratamento com redução dos nutrientes mostraram pior desempenho em relação às aves da dieta sem redução dos nutrientes. Não houve efeito da matéria seca na digestibilidade e na retenção de cálcio. A adição da combinação enzimática melhorou a digestibilidade da proteína e a retenção de fósforo. Houve interação quanto à energia digestível, com efeito apenas nas dietas sem redução dos nutrientes, com maiores valores nas dietas suplementadas.

Termos para indexação: amilase, energia, fitase, fósforo, protease.

\section{Exogenous enzymes in the performance and nutrient ileal digestibility of broiler chickens}

\begin{abstract}
The objective of this work was to evaluate the effect on the performance and nutrient ileal digestibility of broiler chickens, of the phytase combination with the enzyme complex of amylase, protease and xylanase in corn-soybean meal diets, formulated with or without reduction in energy, calcium and phosphorus levels. The experimental design was completely randomized with factorial arrangement $2 \times 2$, with two control diets: with and without nutrient reduction, and two supplementations for each control (with and without addition of phytase and enzyme complex of amylase, protease and xylanase), with ten replicates of 40 chicks. The ileal digesta were collected in the $43^{\text {rd }}$ day of age, in order to determine digestible energy and digestibility coefficients of crude protein, dry matter, calcium and phosphorus. The performance showed interaction for all the parameters analyzed. The broilers fed with nutrient reduction showed inferior feed intake, body weight gain and feed conversion than those fed without nutrient reduction. There was no effect of enzymes and diet control on dry matter and calcium retention. The enzyme combination inclusion improved the protein digestibillity and phosphorus retention compared to control diet. There was interaction for digestible energy, with effects only in without nutrient reduction with best values in supplemented diets.
\end{abstract}

Index terms: amylases, energy, phytase, phosphorus, protease.

\section{Introdução}

A alimentação representa a maior parte dos custos na produção avícola; medidas para reduzir esses custos podem significar lucro para o setor. O aperfeiçoamento da biotecnologia permitiu o lançamento de produtos no mercado que, adicionados à ração, proporcionam melhores índices de produtividade e eficiência alimentar em frangos de corte.
Um desses produtos para nutrição animal são as enzimas que, segundo Butollo (2002), são micronutrientes da alimentação classificados como pró-nutrientes. As enzimas exógenas, nas dietas de frangos de corte, melhoram a digestibilidade dos nutrientes, por meio da redução de fatores anti-nutricionais que promovem a quebra dos componentes da fibra e aumentam a disponibilidade de nutrientes para a digestão. Isto 
proporciona melhora no desempenho das aves (Fuente \& Soto-Salanova, 1997), além de causar redução na síntese de enzimas endógenas e, em consequiência, o organismo tem mais aminoácidos disponíveis para a síntese protéica (Zanella et al., 1999).

O nutricionista escolhe a forma de suplementação enzimática, por meio de duas abordagens econômicas que consideram a incorporação de enzimas exógenas nas formulações das dietas. Uma aplicação mais simples e provavelmente mais prática, chamada de "over the top" (por cima), para melhorar o desempenho de forma mais econômica, consiste em suplementar as enzimas com uma formulação padrão, sem alterar os níveis nutricionais. A alternativa seria alterar a formulação da ração, por meio da redução dos nutrientes, e adição de enzimas exógenas para restaurar o valor nutricional da dieta-padrão que visa o mesmo desempenho de uma dieta com os níveis nutricionais recomendados.

O objetivo deste trabalho foi avaliar o efeito da combinação de enzimas comerciais fitase e complexo amilase, protease e xilanase, em dietas à base de milho e farelo de soja, no desempenho e na digestibilidade ileal de nutrientes (proteína bruta, cálcio e fósforo) e no aproveitamento de energia de frangos de corte.

\section{Material e Métodos}

Este trabalho foi realizado no Setor de Avicultura do Departamento de Zootecnia da Faculdade de Ciências Agrárias e Veterinárias, Unesp, Jaboticabal, SP, com duração de 42 dias. Foram utilizados 1.600 pintos de corte machos da linhagem Cobb, com um dia de idade. Os pintos foram vacinados, no incubatório, contra as doenças de Marek e bouba aviária. Foi utilizado o programa de vacinação: no sétimo dia de idade, contra Gumboro (cepa fraca) via ocular, e no $14^{\circ}$ dia de idade, New Castle e Gumboro (cepa forte), via água de beber, tendo-se utilizado leite em pó como veículo $\left(2 \mathrm{~g} \mathrm{~L}^{-1}\right)$.

$\mathrm{O}$ delineamento experimental utilizado foi o inteiramente casualizado, com dez repetições, com 40 aves em cada unidade experimental, e os tratamentos em esquema fatorial $2 \times 2$ : duas dietas-controle (positivo e negativo), e duas suplementações das combinações enzimáticas - sem adição e com adição de fitase e complexo enzimático. Para a formação das unidades experimentais, os pintos foram pesados individualmente e agrupados por faixa de peso, de forma que todas as parcelas apresentassem pesos médios aproximados. Foram formuladas duas dietas-controle: controle positivo dos níveis nutricionais, para atender às exigências nutricionais em cada fase da criação; e controle negativo, com reduções nos níveis nutricionais de energia metabolizável (EM), Ca e $\mathrm{P}$, conforme a matriz nutricional indicada para as enzimas avaliadas. O complexo enzimático foi composto de: $650 \mathrm{U} \mathrm{kg}^{-1} \mathrm{de}$ xilanase, $1.650 \mathrm{U} \mathrm{kg}^{-1}$ de amilase e $4.000 \mathrm{U} \mathrm{kg}^{-1} \mathrm{de}$ protease, com inclusão de $200 \mathrm{~g} \mathrm{Mg}^{-1}$; e fitase composta de $500 \mathrm{U} \mathrm{kg}^{-1}$ de enzima, com inclusão de $100 \mathrm{~g} \mathrm{Mg}^{-1}$.

A composição centesimal e os níveis calculados dos nutrientes das dietas-controle para a fase inicial -1 a 21 dias de idade - e para fase de crescimento - 22 a 42 dias de idade - estão apresentados na Tabela 1.

Aos 21 e 42 dias de idade, as aves e as rações foram pesadas, para mensuração dos parâmetros de desempenho: peso médio (PM), ganho de peso (GP), consumo médio de ração $(\mathrm{CR})$ e conversão alimentar (CA).

A digestibilidade dos nutrientes foi determinada com o método da digestibilidade ileal. Foi utilizada uma fonte de sílica, Celite, adicionada a todas as dietas experimentais, à proporção de $1 \%$ como indicador indigestível. Com o espaço de $1 \%$ de inerte nas dietas experimentais, foi utilizada areia lavada até os 35 dias de idade, posteriormente substituída por Celite, nas dietas experimentais, e as aves foram submetidas a sete dias de adaptação com indicador indigestível. Aos 43 dias de idade, 20 aves de cada parcela experimental foram abatidas por deslocamento cervical, no total de 200 aves por tratamento. Imediatamente após o abate, o íleo foi exposto por incisão abdominal, e um segmento de $20 \mathrm{~cm}$, que terminava a $4 \mathrm{~cm}$ da junção íleo-cecal, foi removido, e o seu conteúdo foi recolhido em recipiente de plástico identificado por tratamento e repetição. Os frangos foram estimulados a consumir ração, duas horas antes do abate, para evitar que o segmento do íleo coletado apresentasse pouco conteúdo intestinal.

Após a coleta, as digestas foram congeladas para posterior análise. O descongelamento foi realizado à temperatura ambiente, e as digestas foram homogeneizadas, pesadas, novamente congeladas, e submetidas à secagem por liofilização a vácuo, à temperatura de $-40^{\circ} \mathrm{C}$ por 72 horas. Em seguida, as amostras foram moídas em micromoinho A11 basic (IKA) e, com as amostras das rações experimentais, foram encaminhadas ao laboratório. Nas amostras de digesta e de rações, foram determinados os teores de matéria seca (MS), energia bruta (EB), nitrogênio $(\mathrm{N})$, minerais (Ca e $\mathrm{P})$ e cinza ácida insolúvel (CAI). A proteína, analisada pelo método Kjeldahl, e a matéria 
seca (secagem definitiva) foram determinadas de acordo com a metodologia descrita por Silva \& Queiroz (2002). Para a determinação da energia bruta, as amostras foram peletizadas e submetidas à combustão em bomba calorimétrica.

A cinza ácida insolúvel (CAI), fração indigerível presente nas dietas, e digestas foram determinadas pela adaptação da metodologia de Van Keulen \& Young (1977), citados por Santos (2005).

Para a análise dos minerais, a digestão das amostras foi realizada por via úmida (Nogueira \& Souza, 2005). Com os resultados laboratoriais, foram determinados os coeficientes de digestibilidade (CD), matéria seca, proteína bruta, minerais e os valores de energia digestível (ED), calculados com base na análise das dietas e digesta ileal (Sakomura \& Rostagno, 2007).

Os dados foram submetidos à análise de variância pelo procedimento GLM do SAS (SAS Institute, 1996), e as médias foram comparadas pelo teste de Tukey, a $5 \%$ de probabilidade.

\section{Resultados e Discussão}

As médias da energia digestível na matéria seca e matéria natural, coeficiente de digestibilidade da proteína bruta, matéria seca, Ca e $\mathrm{P}$, além dos respectivos resultados da análise de variância, são apresentados na Tabela 2. Não houve interação controle x enzima ( $p>0,05)$, em relação ao coeficiente de digestibilidade da proteína bruta (CDPB) e aos valores da energia digestível (EDMS), mas houve interação quanto à energia digestível na matéria natural $(\mathrm{EDMN})(\mathrm{p}<0,05)$.

$A$ adição da combinação enzimática melhorou o CDPB em relação às dietas não suplementadas. Os melhores resultados, apresentados pela adição de enzimas, deve-se ao efeito complementar das enzimas presentes no complexo enzimático (xilanase, protease e amilase), o que indica que a suplementação, com enzimas exógenas, melhora a digestibilidade das proteínas.

O benefício do aumento da digestibilidade da proteína, promovida pela suplementação enzimática, está mais

Tabela 1. Composição centesimal e níveis calculados dos nutrientes das dietas basais, para a fase inicial ( 1 a 21 dias de idade) e fase de crescimento (22 a 42 dias $)^{(1)}$.

\begin{tabular}{|c|c|c|c|c|}
\hline \multirow[t]{2}{*}{ Ingrediente } & \multicolumn{2}{|c|}{ Fase inicial } & \multicolumn{2}{|c|}{ Fase de crescimento } \\
\hline & Positivo & Negativo & Positivo & Negativo \\
\hline Milho & 55,18 & 59,79 & 59,75 & 65,08 \\
\hline Farelo de soja 45 & 37,68 & 36,59 & 30,53 & 28,99 \\
\hline Óleo de soja & 3,60 & 0,63 & 5,32 & 2,02 \\
\hline Sal & 0,346 & 0,345 & 0,305 & 0,304 \\
\hline DL Metionina (99\%) & 0,331 & 0,317 & 0,294 & 0,284 \\
\hline Lisine $\mathrm{HCl}(78 \%)$ & 0,133 & 0,145 & 0,194 & 0,219 \\
\hline Treonina & - & 0,012 & 0,121 & 0,121 \\
\hline Fosfato bicálcico & 1,536 & 0,824 & 1,051 & 0,501 \\
\hline Vitamina $^{(2)}$ & 0,10 & 0,10 & 0,10 & 0,10 \\
\hline Mineral $^{(3)}$ & 0,05 & 0,05 & 0,05 & 0,05 \\
\hline Coccidiostático $^{(4)}$ & 0,05 & 0,05 & 0,05 & 0,05 \\
\hline Inerte $^{(5)}$ & - & - & 1,00 & 1,00 \\
\hline \multirow[t]{2}{*}{ Total } & 100,00 & 100,00 & 100,00 & 100,00 \\
\hline & \multicolumn{4}{|c|}{ Níveis nutricionais } \\
\hline EM (kcal kg-1) & 3.052 & 2.922 & 3.200 & 3.055 \\
\hline Cálcio & 0,90 & 0,78 & 0,85 & 0,73 \\
\hline Fósforo total & 0,64 & 0,51 & 0,52 & 0,42 \\
\hline Fósforo disponível & 0,40 & 0,27 & 0,30 & 0,20 \\
\hline Metionina total & 0,67 & 0,65 & 0,59 & 0,58 \\
\hline Metionina+cistina total & 1,01 & 1,00 & 0,90 & 0,89 \\
\hline Lisina total & 1,29 & 1,28 & 1,15 & 1,14 \\
\hline
\end{tabular}

${ }^{(1)}$ Para a formulação das rações, foi utilizada a composição dos ingredientes da Tabela Brasileira (Rostagno et al., 2005). (2)Suplemento vitamínico para a fase inicial; cada quilograma do produto com: $1.000 \mathrm{mg}$ de ácido fólico, $15.000 \mathrm{mg}$ de ácido pantotênico, $0,5 \mathrm{~g}$ de antioxidante, $40.000 \mathrm{mg}$ de niacina, $300 \mathrm{mg}$ de selênio, $60 \mathrm{mg}$ de biotina, $1.800 \mathrm{mg}$ de vit. B1, $12.000 \mathrm{mg}$ de vit. B12, $6.000 \mathrm{mg}$ de vit. B2, 2.800 mg de vit. B6, 2.000.000 UI de vit. D3, $1.5000 \mathrm{mg}$ de vit. E, $1.800 \mathrm{mg}$ de vit. K3 (inclusão do produto de $1 \mathrm{~kg} \mathrm{Mg}^{-1}$ ); suplemento vitamínico para a fase de crescimento; cada quilograma do produto com: $700 \mathrm{mg}$ de ácido fólico, $13.000 \mathrm{mg}$ de ácido pantotênico, 0,5 g de antioxidante, $35.000 \mathrm{mg}$ de niacina, $300 \mathrm{mg}$ de selênio, $1.600 \mathrm{mg}$ de vit. B1, $10.000 \mathrm{mg}$ de vit. B12, $5.000 \mathrm{mg}$ de vit. B2, 2.600 mg de vit. B6, 1.500.000 UI de vit. D3, $12.000 \mathrm{mg}$ de vit. E, $1.500 \mathrm{mg}$ de vit. K3 (inclusão do produto de $1 \mathrm{~kg} \mathrm{Mg}^{-1}$ ). ${ }^{(3)}$ Suplemento mineral para as fases inicial/crescimento; cada quilograma do produto com: $150.000 \mathrm{mg}$ de manganês, $100.000 \mathrm{mg}$ de zinco, $100.000 \mathrm{mg}$ de ferro, $16.000 \mathrm{mg}$ de cobre, $1.500 \mathrm{mg}$ de iodo (inclusão do produto de $0,5 \mathrm{~kg} \mathrm{Mg}^{-1}$ ). ${ }^{(4)}$ Monensina sódica (20\%), inclusão do produto de $0,5 \mathrm{~kg} \mathrm{Mg}^{-1}$. ${ }^{(5)}$ Os inertes utilizados foram: areia lavada dos 22 aos 35 dias, e Celite dos 35 até aos 42 dias. 
relacionado à redução da produção de aminoácidos endógenos, do que à melhor digestão dos aminoácidos da dieta (Wyatt \& Bedford, 1998). No entanto, tal benefício é maior em poupar o gasto energético, porque a ave gasta menos energia para realizar processos de digestão, o que resulta em mais energia disponível para processos produtivos.

Com o desdobramento da interação $(\mathrm{p}<0,05)$, as aves alimentadas com a dieta-controle negativo apresentaram EDMN inferior às alimentadas com a dieta-controle positivo. A adição enzimática na dieta-controle negativo não proporcionou diferença $(p>0,05)$ na EDMN, entretanto a suplementação na dieta-controle positivo promoveu aumento na ED da dieta. A combinação enzimática melhorou em 1,95\% a EDMS, em relação à dieta não suplementada. Zanella et al. (1999) e Pack \& Bedford (1998) também encontraram aumento na ED, com a suplementação do complexo amilase, protease e xilanase. Tejedor et al. (2001) verificaram que a adição de duas fitases, em dietas deficientes em $\mathrm{Ca}$ e P, aumentou a energia digestível ileal aparente.

As suplementações enzimáticas na dieta-controle negativo não apresentaram melhora na ED, entretanto, proporcionaram aumento no desempenho das aves. Isso pode ter ocorrido pelo fato de as aves pouparem energia com a redução da produção de endógeno, ocasionada pela suplementação enzimática nessas dietas (Wyatt \& Bedford, 1998).

Não houve interação controle $x$ enzima $(p>0,05)$ quanto ao coeficiente de digestibilidade da matéria seca (CDMS) e coeficiente de digestibilidade do cálcio
(CDCa), embora o coeficiente de digestibilidade do $\mathrm{P}$ (CDP) tenha apresentado efeito na interação estudada ( $p>0,05)$. Com base nos resultados obtidos para CDMS, não foram observadas diferenças $(\mathrm{p}>0,05)$ para nenhum fator estudado. Santos (2005), ao comparar os CDMS de dietas suplementadas com fitase (500 U), não encontrou diferenças no CDMS. Todavia, Zanella et al. (1999) e Rodrigues et al. (2003) encontraram diferenças nos CDMS, com a suplementação enzimática (amilase, protease e xilanase). Marron et al. (2001) encontraram melhora na digestibilidade ileal da MS e na conversão alimentar, com a suplementação de xilanase.

O CDMS reflete a digestibilidade dos nutrientes, e o aumento na digestibilidade da MS indica maior absorção dos nutrientes de uma dieta. Santos (2005) constatou que o aumento do CDMS, com a suplementação de fitas em diferentes níveis, é explicado pela melhora na digestibilidade de nutrientes, como proteína bruta e minerais, e no aproveitamento da energia, proporcionados pelas suplementações de enzimas nas dietas. Entretanto, neste trabalho, a melhora com a suplementação enzimática, na digestibilidade de proteínas e minerais, não se refletiu no CDMS.

De acordo com o desdobramento da interação CDP, a combinação enzimática melhorou o CDP em ambos os controles. Por outro lado, não houve efeito em relação a qualquer interação estudada no CDCa. Cowieson \& Adeola (2005) não encontraram diferenças nos coeficientes de digestibilidade do $\mathrm{P}$, em dietas com os níveis nutricionais reduzidos e suplementadas com combinação de fitase e do complexo amilase, protease

Tabela 2. Probabilidades obtidas na análise de variância e valores médios de energia digestível na matéria seca e na matéria natural, e dos coeficientes da proteína bruta, matéria seca, cálcio e fósforo ${ }^{(1)}$.

\begin{tabular}{|c|c|c|c|c|c|c|c|c|}
\hline \multirow[t]{3}{*}{ Variável $^{(2)}$} & \multirow[t]{3}{*}{ Enzimas } & \multicolumn{2}{|c|}{ Controles } & \multirow[t]{3}{*}{ Médias } & \multirow{2}{*}{\multicolumn{3}{|c|}{$\begin{array}{c}\text { Probabilidades } \\
\text { (teste F) }\end{array}$}} & \multirow{3}{*}{$\begin{array}{l}\text { CV } \\
(\%)\end{array}$} \\
\hline & & \multirow[t]{2}{*}{ Positivo } & \multirow{2}{*}{ Negativo } & & & & & \\
\hline & & & & & Enzima & Controle & Interação & \\
\hline \multirow[t]{3}{*}{$\overline{\mathrm{CDPB}(\%)}$} & Sem adição & 76,18 & 75,90 & $76,03 \mathrm{~b}$ & 0,0009 & $\mathrm{~ns}$ & $\mathrm{~ns}$ & 2,38 \\
\hline & Adição & 78,05 & 78,31 & $78,18 \mathrm{a}$ & & & & \\
\hline & Médias & 77,16 & 77,10 & & & & & \\
\hline \multirow[t]{3}{*}{$\mathrm{ED}\left(\mathrm{cal} \mathrm{g}^{-1} \mathrm{MS}\right)$} & Sem adição & 3.175 & 3.063 & $3.119 \mathrm{~b}$ & 0,0086 & $<0,0001$ & $\mathrm{~ns}$ & 2,17 \\
\hline & Adição & 3.292 & 3.081 & $3.180 \mathrm{a}$ & & & & \\
\hline & Médias & $3.234 \mathrm{~A}$ & $3.072 \mathrm{~B}$ & & & & & \\
\hline \multirow[t]{2}{*}{$\left.\overline{\mathrm{ED}(\mathrm{cal} \mathrm{g}}{ }^{-1} \mathrm{MN}\right)$} & Sem adição & $2.849 \mathrm{bA}$ & $2.755 \mathrm{aB}$ & & 0,0143 & $<0,0001$ & 0,0091 & 2,29 \\
\hline & Adição & $2.965 \mathrm{aA}$ & $2.751 \mathrm{aB}$ & & & & & \\
\hline \multirow[t]{3}{*}{ CDMS (\%) } & Sem adição & 68,18 & 69,03 & 68,62 & ns & ns & ns & 2,78 \\
\hline & Adição & 70,05 & 69,68 & 69,86 & & & & \\
\hline & Médias & 69,16 & 69,35 & & & & & \\
\hline \multirow[t]{3}{*}{$\overline{\mathrm{CDCa}(\%)}$} & Sem adição & 44,33 & 45,72 & 45,04 & $\mathrm{~ns}$ & $\mathrm{~ns}$ & ns & 14,21 \\
\hline & Adição & 47,80 & 47,81 & 47,77 & & & & \\
\hline & Médias & 46,15 & 46,81 & & & & & \\
\hline \multirow[t]{2}{*}{$\mathrm{CDP}(\%)$} & Sem adição & $56,70 \mathrm{bA}$ & $50,90 \mathrm{bB}$ & & $<0,0001$ & $<0,0001$ & 0,0286 & 4,13 \\
\hline & Adição & $67,03 \mathrm{aA}$ & $65,19 \mathrm{aA}$ & & & & & \\
\hline
\end{tabular}

(1)Médias seguidas por letras iguais, maiúsculas nas linhas e minúsculas nas colunas, não diferem entre si pelo teste de Tukey, a 5\% de probabilidade. ${ }^{(2)} \mathrm{CDPB}$, coeficiente de digestibilidade da proteína bruta; ED, energia digestível; CDMS, coeficiente de digestibilidade da matéria seca;

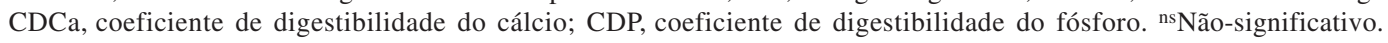


e xilanase. Santos (2005) comparou dietas, com suplementação e sem suplementação de fitase e não encontrou diferenças nos coeficientes de digestibilidade ileal do cálcio, porém observou piores resultados no coeficiente de digestibilidade ileal do fósforo na dieta-controle positivo.

A melhora na digestibilidade dos minerais é atribuída à suplementação com fitase, combinada ao complexo enzimático. Segundo Sebastian et al. (1996), a fitase quebra o complexo fitato-mineral e libera minerais para absorção, o que reduz sua excreção e, conseqüentemente, aumenta sua digestibilidade. A melhora na digestibilidade do $\mathrm{Ca}$ e $\mathrm{P}$, nas dietas-controle negativo com suplementação enzimática, ocorre em razão de a fitase ser mais eficiente em dietas com níveis de $\mathrm{Ca}$ e $\mathrm{P}$ abaixo dos níveis recomendado, o que para Lesson (1999) evita redução significativa do efeito da fitase.

O coeficiente de digestibilidade do $\mathrm{P}$, obtido para o controle negativo $(50,90 \%)$, foi inferior ao encontrado para o controle positivo $(56,70 \%)$. Era esperado que os coeficientes dos minerais provenientes da dieta-controle negativo fossem superiores aos da dieta-controle positivo. Segundo Um \& Paik (1999) e Ravindran et al. (2001), as aves apresentam a capacidade de aumentar a retenção de minerais necessários para manter as funções fisiológicas, à medida que reduzem os níveis na dieta. Entretanto, os resultados podem ser explicados pelo aumento da relação Ca:P com a redução dos níveis nutricionais, o que pode proporcionar elevação no $\mathrm{pH}$ intestinal, pela redução da solubilidade dos minerais e, conseqüentemente, pela diminuição da digestibilidade desses minerais, conforme Shafey (1993).

Na Tabela 3, são apresentadas as médias das variáveis de desempenho e as respectivas probabilidades, obtidas nas análises de variâncias na fase inicial da criação. De acordo com os resultados, houve efeito significativo da interação dieta $x$ enzima $(\mathrm{p}<0,05)$ para: peso médio, ganho de peso e consumo de ração. Com o desdobramento da interação $(\mathrm{p}<0,05)$, houve efeito da suplementação enzimática apenas na dieta-controle negativo.

A combinação enzimática na dieta-controle negativo aumentou o consumo em 10\%. Esses dados discordam de Conte et al. (2003), que não encontraram diferenças no consumo dessa dieta com a utilização de xilanase e a combinação dessa enzima com fitase, mas encontraram aumento com a suplementação de fitase, em frangos de corte aos 21 dias de idade.

De acordo com os dados apresentados por Olukosi et al. (2007), as glicosidases degradam a camada de PNAs da membrana celular, o que facilita o acesso da fitase ao fitato armazenado na membrana da parede celular. Os mesmos autores encontraram melhora no desempenho e na digestibilidade de nutrientes com combinação enzimática de fitase e complexo amilase, xilanase e protease, em dietas de frangos corte.

$\mathrm{O}$ baixo consumo da dieta-controle negativo, sem suplementação a suplementação enzimática, ocorre principalmente pela deficiência de $\mathrm{P}$ nessa dieta. Em dietas com redução nos níveis nutricionais, as aves tentam compensar a deficiência com maior ingestão; entretanto, a deficiência em $\mathrm{P}$ provoca redução no consumo de alimento (Viveiros et al., 2002). A adição da fitase nas dietas provoca a ruptura do complexo fósforo-ácido fítico, o que libera o mineral para ser absorvido, e inativa o efeito depressor de sua deficiência sobre o consumo de ração (Santos, 2005). Essa resposta pode ser observada pelos resultados da digestibilidade,

Tabela 3. Probabilidades obtidas na análise de variância, coeficientes de variação e médias das variáveis de desempenho de frangos de corte, na fase inicial (1 a 21 dias) $)^{(1)}$.

\begin{tabular}{|c|c|c|c|c|c|c|c|c|}
\hline \multirow[t]{3}{*}{ Variável $^{(2)}$} & \multirow[t]{3}{*}{ Enzimas } & \multicolumn{2}{|c|}{ Controles } & \multirow[t]{3}{*}{ Médias } & \multirow{2}{*}{\multicolumn{3}{|c|}{$\begin{array}{l}\text { Probabilidades } \\
\text { (teste F) }\end{array}$}} & \multirow{3}{*}{$\begin{array}{l}\text { CV } \\
(\%)\end{array}$} \\
\hline & & \multirow[t]{2}{*}{ Positivo } & \multirow[t]{2}{*}{ Negativo } & & & & & \\
\hline & & & & & Enzima & Controle & Interação & \\
\hline \multirow[t]{2}{*}{$\overline{P M}(\mathrm{~g})$} & Sem adição & $866 \mathrm{aA}$ & $741 \mathrm{bB}$ & & 0,0001 & 0,0001 & 0,0015 & 2,56 \\
\hline & Adição & $889 \mathrm{aA}$ & $811 \mathrm{aB}$ & & & & & \\
\hline \multirow[t]{2}{*}{$\overline{\mathrm{CR}}\left(\mathrm{g}\right.$ ave $\left.{ }^{-1}\right)$} & Sem adição & $1.125 \mathrm{aA}$ & $1.035 \mathrm{bB}$ & & 0,0002 & 0,0001 & 0,0133 & 3,11 \\
\hline & Adição & $1.141 \mathrm{aA}$ & $1.109 \mathrm{aA}$ & & & & & \\
\hline \multirow[t]{2}{*}{$\mathrm{GP}\left(\mathrm{g} a v \mathrm{e}^{-1}\right)$} & Sem adição & $824 \mathrm{aA}$ & $699 \mathrm{bB}$ & & 0,0001 & 0,0001 & 0,0014 & 2,69 \\
\hline & Adição & $847 \mathrm{aA}$ & $769 \mathrm{aB}$ & & & & & \\
\hline \multirow[t]{3}{*}{$\mathrm{CA}\left(\mathrm{g} \mathrm{g}^{-1}\right)$} & Sem adição & 1,365 & 1,481 & $1,423 b$ & 0,0297 & 0,0001 & $\mathrm{~ns}$ & 2,74 \\
\hline & Adição & 1,348 & 1,443 & $1,395 \mathrm{a}$ & & & & \\
\hline & Médias & $1,355 \mathrm{a}$ & $1,455 \mathrm{~b}$ & & & & & \\
\hline
\end{tabular}

${ }^{(1)}$ Médias seguidas por letras iguais, maiúsculas nas linhas e minúsculas nas colunas, não diferem entre si pelo teste de Tukey, a 5\% de probabilidade.

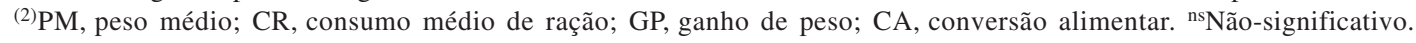


com o melhor aproveitamento do mineral proporcionado pela suplementação de fitase nas dietas, o que reflete no aumento do consumo de ração e, conseqüentemente, na melhora de outros parâmetros de desempenho.

No entanto, a suplementação enzimática nas dietascontrole positivo não teve efeito no consumo de ração, isso pode ser explicado pelo fato de os níveis nutricionais dessas dietas atenderem adequadamente às necessidades das aves. $\mathrm{O}$ aumento do consumo de ração, provocado pela suplementação enzimática, principalmente pela ação da enzima fitase, refletiu na melhora do peso médio e do ganho de peso das aves tratadas com a dieta-controle negativo. A suplementação enzimática nessa dieta promoveu melhora de $10 \%$ no ganho de peso, e de $9,5 \%$ no peso médio.

A conversão alimentar foi influenciada pelas dietas e pela suplementação das combinações enzimáticas $(\mathrm{p}<0,05)$. As aves alimentadas com controle positivo apresentaram melhor conversão alimentar, do que aquelas que receberam a ração controle negativo. A suplementação enzimática melhorou em $2 \%$ a conversão alimentar. Torres et al. (2003) verificaram que a conversão alimentar de frangos de corte, na fase inicial, melhorou quando foi adicionado um complexo de amilase, protease e xilanase nas dietas com maior teor protéico. De acordo com os resultados de digestibilidade da proteína e da conversão alimentar, nessa fase, a inclusão da enzima xilanase no complexo parece complementar o efeito da enzima fitase, na utilização dos nutrientes da dieta, o que melhora o desempenho das aves. Neste trabalho, a melhora dos parâmetros de desempenho das aves, alimentadas com dieta-controle negativo com a suplementação enzimática, foi proporcionado pela melhora da digestibilidade da proteína e fósforo, embora não tenham apresentado melhora na ED e no CDMS.
Dänicke et al. (1999) encontraram ligeira melhora na digestibilidade aparente do $\mathrm{N}$ e da MS, com a suplementação de xilanase nas dietas, embora não tenham observado diferenças no peso médio e consumo de ração. Marsman et al. (1997) encontraram aumento na digestibilidade ileal da proteína bruta, com a suplementação de carboidrase e protease, embora não tenham verificado melhoria no desempenho, no período dos 7 aos 25 dias.

Na fase de criação (1 a 21 dias), as dietas-controle positivo apresentaram ligeira melhora com a suplementação enzimática, embora não significativa, o que mostra que a suplementação "over the top" é mais recomendada na fase inicial, em razão da imaturidade inata do sistema enzimático das aves jovens.

Na Tabela 4, são apresentadas as médias das variáveis de desempenho e as respectivas probabilidades, obtidas nas análises de variâncias no período total da criação (1 a 42 dias de idade). Os resultados apresentados são semelhantes aos da fase inicial ( 1 a 21 dias). Houve efeito significativo da interação dieta $x$ enzima $(p<0,05)$, em todas as variáveis estudadas.

Nos desdobramentos das interações $(p<0,05)$, para todas as variáveis estudadas nessa fase, e na avaliação de cada controle, pode-se observar que não houve diferenças significativas no controle positivo, entretanto houve uma melhora no desempenho das aves do controle negativo, quando as dietas foram suplementadas.

A adição enzimática na dieta-controle negativo promoveu melhora de 16,11,4, 16,2 e 4,2\% no peso médio, ganho de peso, consumo de ração e conversão alimentar, respectivamente. Esses dados discordam de Lima et al. (2002), que ao suplementar as dietas com amilase e protease, não encontraram diferenças no consumo e na conversão alimentar no período de 1 a 42 dias de idade.

Tabela 4. Probabilidades obtidas na análise de variância, coeficientes de variação e médias das variáveis de desempenho de frangos de corte, no período total da criação (1 a 42 dias $)^{(1)}$.

\begin{tabular}{|c|c|c|c|c|c|c|c|}
\hline \multirow[t]{2}{*}{ Variável $^{(-2)}$} & \multirow[t]{2}{*}{ Enzimas } & \multicolumn{2}{|c|}{ Controles } & \multicolumn{3}{|c|}{$\begin{array}{c}\text { Probabilidades } \\
\text { (teste F) }\end{array}$} & \multirow[t]{2}{*}{$\begin{array}{l}\text { CV } \\
(\%)\end{array}$} \\
\hline & & Positivo & Negativo & Enzima & Controle & Interação & \\
\hline \multirow[t]{2}{*}{$\overline{\mathrm{PM}(\mathrm{g})}$} & Sem adição & $2.770 \mathrm{aA}$ & $2.314 \mathrm{bB}$ & 0,0001 & 0,0001 & 0,0001 & 1,78 \\
\hline & Adição & $2.809 \mathrm{aA}$ & $2.683 \mathrm{aB}$ & & & & \\
\hline \multirow[t]{2}{*}{ CR $\left(\right.$ g ave $\left.^{-1}\right)$} & Sem adição & $4.261 \mathrm{aA}$ & $3.825 \mathrm{bB}$ & 0,0001 & 0,0001 & 0,0001 & 1,83 \\
\hline & Adição & $4.270 \mathrm{aA}$ & $4.260 \mathrm{aA}$ & & & & \\
\hline \multirow[t]{2}{*}{$\mathrm{GP}\left(\mathrm{g} a v \mathrm{e}^{-1}\right)$} & Sem adição & $2.728 \mathrm{aA}$ & $2.272 \mathrm{bB}$ & 0,0001 & 0,0001 & 0,0001 & 1,81 \\
\hline & Adição & $2.767 \mathrm{aA}$ & $2.641 \mathrm{aB}$ & & & & \\
\hline \multirow[t]{2}{*}{$\overline{\mathrm{CA}}\left(\mathrm{g} \mathrm{g}^{-1}\right)$} & Sem adição & $1,562 \mathrm{aA}$ & $1,684 \mathrm{bB}$ & 0,0001 & 0,0003 & 0,0268 & 2,12 \\
\hline & Adição & $1,543 \mathrm{aA}$ & $1,613 \mathrm{aB}$ & & & & \\
\hline
\end{tabular}

${ }^{(1)}$ Médias seguidas por letras iguais, maiúsculas nas linhas e minúsculas nas colunas, não diferem entre si pelo teste de Tukey, a 5\% de probabilidade.

(2)PM, peso médio; CR, consumo médio de ração; GP, ganho de peso; CA, conversão alimentar. 
A melhora no desempenho das aves, alimentadas com a suplementação enzimática na dieta-controle negativo, deve-se à melhora da digestibilidade dos minerais e proteína. $\mathrm{O}$ fato de as aves alimentadas com dietas-controle negativo apresentarem melhora no desempenho e não apresentarem aumento na ED pode ser explicado pela redução na produção de endógenos, proporcionada pela suplementação enzimática (Wyatt \& Bedford, 1998), o que se reflete indiretamente em não aproveitamento da energia, uma vez que as aves gastariam menos energia para produção de endógeno e disporiam de mais energia para os processos de produção.

\section{Conclusão}

A suplementação da combinação enzimática, em dietas com níveis nutricionais reduzidos, melhora o aproveitamento de proteína bruta, cálcio e fósforo, e se reflete no desempenho das aves, em razão do melhor aproveitamento dos nutrientes; entretanto, essas aves não apresentam desempenho igual ao das alimentadas com dietas com os níveis nutricionais recomendados, sem a suplementação enzimática.

\section{Referências}

BUTOLLO, J.E. Qualidade de ingredientes na alimentação animal. Campinas: CBNA, 2002. 430p.

CONTE, A.J.; TEIXEIRA, A.S.; FIALHO, E.T.; SCHOULTEN, N.A.; BERTICHINI, A.N. Efeito da fitase e xilanase sobre o desempenho e as característica ósseas de frangos de corte alimentados com dietas contendo farelo de arroz. Revista Brasileira Zootecnia, v.32, p.1147-1156, 2003.

COWIESON, A.J.; ADEOLA, O. Carbohydrases, protease and phytase have an additive beneficial effect in nutritionally marginal diets for broiler chicks. Poultry Science, v.84, p.1860-1867, 2005.

DÄNICKE, S.; VAHJEN, W.; SIMON, O.; JEROCH, H. Effects of dietary fat type and xylanase supplementation to rye-based broiler diets on selected bacterial groups adhering to the intestinal epithelium, on transit time of feed and on nutrient digestibility. Poultry Science, v.78, p.1292-1299, 1999.

FUENTE, J.M.; SOTO-SALANOVA, M.F. Utilización de enzimas para mejorar el valor nutritivo de las dietas maíz-sorgo/soja en avicultura. Selecciones Avícolas, v.39, p.271-275, 1997.

LESSON, S. Enzimas para aves. In: SIMPÓSIO INTERNACIONAL SOBRE NUTRIÇÃO DE AVES, 1999, Campinas. Anais. Campinas: Facta, 1999. p.173-185.

LIMA, A.C.F.; HARNICH, F.A.R.; MACARI, M.; PIZAURO JÚNIOR, J.M. Avaliação do desempenho de frangos de corte alimentados com suplementação enzimática e probiótica. Ars Veterinaria, v.18, p.153-157, 2002.
MARRON, L.; BEDFORD, M.R.; McCRACKEN, K.J. The effects of adding xylanase, vitamin $C$ and copper sulphate to wheat-based diets on broiler performance. British Poultry Science, v.42, p.493500, 2001.

MARSMAN, G.J.P.; GRUPPEN, H.; VAN DER POEL, A.F.; VERSTEGEN, M.W.; VORAGEN, A.G. The effect of thermal processing and enzyme treatments of soybean meal on growth performance, ileal nutrient digestibilities and chyme characteristics in broiler chickens. Poultry Science, v.76, p.864-872, 1997.

NOGUEIRA, A.R.A.; SOUZA, G.B. Manual de laboratórios: solo, água, nutrição animal e alimentos. São Carlos: Embrapa Pecuária Sudeste, 2005. 313p.

OLUKOSI, O.A.; COWIESON, A.J.; ADEOLA, O. Age-related influence of a cocktail of xylanase, amylase, and protease or phytase individually or in combination in broilers. Poultry Science, v.86, p.77-86, 2007.

PACK, M.; BEDFORD, M. Feed enzymes for corn-soybean broiler diets: a new concept to improve nutritional value and economics. World's Poultry Science Journal, v.13, p.87-93, 1997.

RAVINDRAN, V.; SELLE, P.H.; RAVIDRAN, G.; MOREL, P.C.H.; KIES, A.K.; BRYDEN, W.L. Microbial phytase improves performance, apparent metabolizable energy, and ileal amino acid digestibility of broilers fed a lysine-deficient diet. Poultry Science, v.80, p.338-344, 2001.

RODRIGUES, P.B.; ROSTAGNO, H.S.; ALBINO, L.F.T.; GOMES, P.C.; BARBOZA, W.A.; TOLEDO, R.S. Desempenho de frangos de corte, digestibilidade de nutrientes e valores energéticos de rações formuladas com vários milhos, suplementadas com enzimas. Revista Brasileira de Zootecnia, v.32, p.171-182, 2003.

ROSTAGNO, H.S. Tabelas brasileiras para aves e suínos: composição de alimentos e exigências nutricionais. 2.ed. Viçosa: UFV, 2005. 186p.

SAKOMURA, N.K.; ROSTAGNO, H.S. Métodos de pesquisa em nutrição de monogástricos. Jaboticabal: Funep, 2007. 283p.

SANTOS, F.R. Efeito da suplementação com fitase sobre o desempenho e digestibilidade de nutrientes para frangos de corte. 2005. 99p. Dissertação (Mestrado) - Universidade Estadual Paulista, Jaboticabal.

SAS INSTITUTE. SAS/STAT: user's guide. 11.ed. Cary: SAS Institute, 1996. 842p.

SEBASTIAN, S.; TOUCHBURN, S.P.; CHAVEZ, E.R.; LAGUE, P.C. The effects of supplemental microbial phytase on the performance and utilization of dietary calcium, phosphorus, copper and zinc in broiler chickens fed corn-soybean diets. Poultry Science, v.75, p.729-736, 1996.

SHAFEY, T.M. Calcium tolerance of growing chickens: effect of ratio of dietary calcium to non phytate phosphorus. World's Poultry Science, v.49, p.5-18, 1993.

SILVA, D.J.; QUEIROZ, A.C. Análise de alimentos: métodos químicos e biológicos. 3.ed. Viçosa: UFV, 2002. 235p.

TEJEDOR, A.A.; ALBINO, LF.T.; ROSTAGNO, H.S.; VIEITES, F.M. Efeito da adição da enzima fitase sobre o desempenho e a digestibilidade ileal de nutrientes. Revista Brasileira Zootecnia, v.30, p.802-808, 2001. 
TORRES, D.M.; TEIXEIRA, A.S.; RODRIGUES, P.B.; BERTECHINI, A.G.; FREITAS, R.T.F.; SANTOS, E.C. Eficiência das enzimas amilase, protease e xilanase sobre o desempenho de frangos de corte. Ciência e Agrotecnologia, v.27, p.1401-1408, 2003.

UM, J.S.; PAIK, I.K. Effects of microbial phytase supplementation on egg production, eggshell quality, and mineral retention of laying hens fed different levels of phosphorus. Poultry Science, v.78, p.75-79, 1999.

VIVEIROS, A.; BRENES, A.; ARIJA, I.; CENTENO, C. Effects of microbial phytase supplementation on mineral utilization and serum enzyme activities in broiler chicks fed different levels of phosphorus. Poultry Science, v.81, p.1172-1183, 2002.

WYATT, C.L.; BEDFORD, M.R. O uso de enzimas nutricionais para maximizar a utilização de nutrientes pelo frango de corte em dietas à base de milho: recentes progressos no desenvolvimento e aplicações práticas. In: SEMINÁRIO TÉCNICO FINNFEEDS, 1998, Curitiba. Anais. Curitiba: Finnfeeds, 1998. p.2-12.

ZANELLA, I.; SAKOMURA, N.K.; SILVERSIDES, F.G.; FIQUEIRDO, A.; PACK, M. Effect of enzyme supplementation of broiler diets based on corn and soybeans. Poultry Science, v.78, p.561-568, 1999.

Recebido em 13 de dezembro de 2007 e aprovado em 20 de maio de 2008 